\title{
Reversing subcellular remodelling in the rescue of depressed contractility
}

\author{
Ellis A Christian MD¹, Yenal I Harper MD¹, Salvatore Mancarella PhD², Rohan Goswami MD¹, \\ Beatrix M Ramos MD ${ }^{1}$, Karl T Weber MD ${ }^{1}$
}

\begin{abstract}
EA Christian, YI Harper S Mancarella, R Goswami, BM Ramos, KT Weber. Reversing subcellular remodelling in the rescue of depressed contractility. Curr Res Cardiol 2016;3(3):75-78.
\end{abstract}

Systolic heart failure with reduced ejection fraction has long been regarded as a heart with an irreversible depression in myocardial contractility. Improvements in ventricular function with recovery of contractility, however, have occurred during a period of cardiac unloading provided by a continuous-flow left ventricular assist device. The authors briefly review subcellular remodelling involved in the appearance of depressed cardiomyocyte work. Redox-sensitive deiodinase 3 (Dio3) is held responsible for a reduction of intracellular thyroid hormone signalling with the re-expression of a fetal gene program that includes slow $\beta$-myosin heavy chain. The attendant reduction in contractile work is an adaptation that preserves myocyte efficiency (work/energy consumed) and viability. Neutralizing oxidative stress and Dio3 is integral to the reversal of subcellular remodelling and rescue of depressed contractility.

Key Words: Fetal gene program; Heart failure; Myocardial contractility; Myocyte efficiency; Thyroid hormone signalling

\begin{abstract}
$\mathrm{C}$ ontractility is the property of cardiac muscle that determines myocyte shortening independent of muscle length before shortening (preload determined) and the load muscle encounters during shortening (afterload determined) (1). For the heart, it has been divided into intrinsic and manifest components (2): intrinsic contractility - a function of cardiomyocyte contractile protein composition and its handling of calcium as it shuttles between intracellular domains; and manifest contractility - determined by substances released within the heart (eg, from adrenergic nerve endings or its myocytes and nonmyocyte cells) or circulating hormones (eg, catecholamines, angiotensin II) and their cognate receptor binding.

Contractility is often expressed as a global measure of the work performed by the myocardium. For example, ejection fraction (EF), or stroke volume displaced from a given end-diastolic volume, is a frequently used index of contractility. Systolic heart failure is suggested when EF falls below the range established for normal hearts. Fallen EF is presumed to imply an irreversibly failing heart - one that would not likely recover over time with or without pharmacological support. However, the recent experience with continuous-flow left ventricular-assist devices (CF-LVAD) suggests otherwise. Following a period of device-induced unloading, depressed EF has improved and remained stable in some patients to enable device removal (destination therapy) (3-5).

The present mini-review addresses subcellular remodelling and its potential for reversal in the rescue of depressed contractility. Dr Naranjan S Dhalla (Winnipeg, Manitoba) and coworkers have contributed substantively to our understanding of subcellular remodelling and its potential for prevention and recovery (vide infra).
\end{abstract}

\section{SUBCELLULAR REMODELLING}

Contractility is largely a function of subcellular events occurring within cardiomyocytes (6). Studies conducted by Lompre et al (7) and reported in 1979 would draw attention to the dynamic shift between fast (alpha $[\alpha]$ ) and slow (beta $[\beta]$ ) myosin heavy chain (MHC) composition when the heart hypertrophied in response to a pressure overload or with hypothyroidism, and that was reflected in a reduced speed and extent of ventricular shortening. Alpert and Mulieri (8) would draw attention to how these responses were, in fact, myothermic adaptations (work performed and heat lost/energy consumed). Gustafson et al (9) would further identify the important role of intracellular thyroid hormone signalling in regulating the ratio of $\alpha-\mathrm{MHC} / \beta-\mathrm{MHC}$.

The studies conducted by Dhalla et al (10) would reveal the plastic behaviour of subcellular elements that appear in the hypertrophied heart. This included the dynamic nature of the biochemical composition and molecular structure of myocytes based on changes in cardiac gene expression, including shifts between $\alpha$ - and $\beta$-MHC isoforms and downregulation of sarcoplasmic reticulum $\mathrm{Ca}^{2+}$ ATPase (SERCA2a) in response to diverse stressor states. Ventricular function was determined by events involving these contractile proteins and handling of $\mathrm{Ca}^{2+}$ and their potential for preventing or reversing such remodelling by pharmacological agents interfering with neurohormonal activation (11-17). The term 'subcellular remodelling' would be coined to identify iterations in intracellular responses that followed acute myocardial infarction, ischemia/reperfusion injury, chemical-induced diabetes, and hypo- or hyperthyroidism. In each of these stressor states, the $\beta$-MHC response, or slow phenotype, was upregulated along with a re-expression of the atrial (ANP) and brain (BNP) family of natriuretic peptides, while the fast $\alpha-\mathrm{MHC}$ isoform along with SERCA2a were downregulated. This myocyte dedifferentiation would recapitulate the fetal gene program with a reduction in the speed and extent of contractile work. Consequent depressed indexes of contractility would suggest the myocardium was failing. However, when viewed in terms of myocyte work performed relative to energy consumed, the heart had adapted to preserve its efficiency and myocyte viability.

A further cardioprotective adaptation operative during hyperadrenergic stressor states is the downregulation of positive inotropic $\beta_{1}$ and $\beta_{2}$ adrenergic receptors, while negative inotropic $\beta_{3}$ receptors are upregulated to offset catecholamine excess (18).

Collectively, these protective myocyte transformations occur based on intracellular signalling, which links mitochondrial and nuclear responses with cytosolic events to conserve myocyte energetics.

Some have argued the subcellular remodelling that accompanies hypertrophy with reduced contractile work is pathological and increases the risk for heart failure and, accordingly, suggest hypertrophy should be prevented (19-22). The fetal gene program and reduced contractile work of the hypertrophied heart is not equipped to accommodate acute increments in ventricular pressure work imposed by the placement of a constrictive aortic band or infusion of angiotensin II in pressor dosage.

${ }^{1}$ Division of Cardiovascular Diseases; ${ }^{2}$ Department of Physiology, University of Tennessee Health Science Center, Memphis, Tennessee, USA

Correspondence and reprints: Dr Karl T Weber, Division of Cardiovascular Diseases, University of Tennessee Health Science Center, 956 Court Avenue, Suite A312, Memphis, Tennessee 38163, USA. Telephone 901-448-5750, fax 901-448-8084, e-mail KTWeber@uthsc.edu 


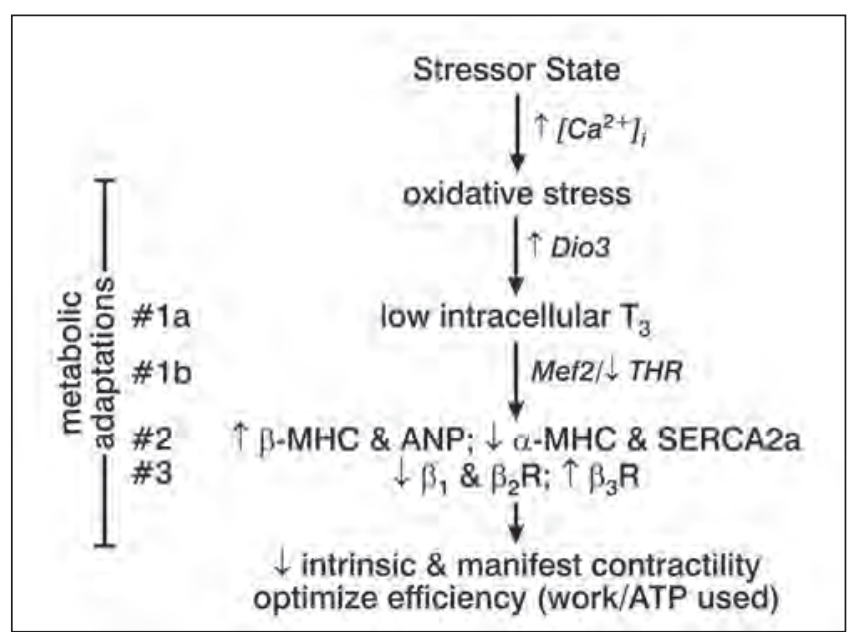

Figure 1) A pathophysiological scenario that overviews a common pathophysiological stressor state leading to cardiomyocyte intracellular $\left[\mathrm{Ca}^{2+}\right] i$ overload and oxidative stress with subsequent upregulated deiodinase (Dio) 3 activity and resultant subcellular remodelling. This includes low intracellular T3 signalling and cell dedifferentiation with recapitulation of the fetal gene phenotype. Ensuing adaptations (\#1 - \#3) accompany fetal gene re-expression, including $\beta$ myosin heavy chain ( $\beta-\mathrm{MHC}$ ) and atrial natriuretic peptide (ANP) coupled to downregulated $\alpha \mathrm{MHC}$ and SERCA2a, together with $\beta_{1}$ and $\beta_{2}$ adrenergic and thyroid hormone $(T H)$ receptors $(R)$, while $\beta_{3} R$ are upregulated. Collectively, these adaptations eventuate in depressed intrinsic and manifest myocardial contractility with reduced contractile work relative to energy expenditure to optimize myocyte efficiency (see text). Reproduced with permission from Weber KT. Depressed myocardial contractility. Can it be rescued? Am J Med Sci 2016 (In press)

The resultant afterload mismatch (23) with reduced shortening and ventricular dilation are cited as further evidence of pathological hypertrophy.

Myocyte hypertrophy and subcellular remodelling, however, are reversible following ventricular unloading such as occurs with the replacement of a stenotic aortic valve $(24,25)$ or constrictive aortic band (26-28), CF-LVAD support (3-5) or with antihypertensive agents (29). Depressed contractility is reversible and, therefore, can be rescued.

\section{DEIODINASE 3 AND INTRACELLULAR THYROID HORMONE SIGNALLING}

Intracellular thyroid hormone $(\mathrm{TH})$ signalling regulates myocyte expression of contractile proteins: high TH favours fast $\alpha$-MHC as dominates the normal heart or with hyperthyroidism, while low $\mathrm{TH}$ promotes slow $\beta$-MHC of the hypertrophied heart or in hypothyroidism (8). Circulating thyroxine (T4) is deiodinated into biologically active triiodothyronine (T3) by deiodinase (Dio)2. A reduction in Dio2 activity, as occurs with the oxidative stress of acute stressor states, creates a low circulating T3 systemic state referred to as the 'sick euthyroid syndrome' (30). Cardiomyocytes, however, have little or no Dio2 and, therefore, are spared intracellular T3 formation with its potential adverse demand on energy consumption.

Deiodinase (Dio3), a deiodinase that converts both T4 and T3 into inactive metabolites, is similarly activated by oxidative stress (31). Dio3 is present in cardiomyocytes, where it protects these cells from incremental T3 and preserves their efficiency; it is considered metabolic adaptation (\#1a in Figure 1). Dio3 expression and activity are increased in the hypertrophied ventricle associated with pressure overload and which follows infarction or induction of diabetes (32-34). Low intracellular T3 regulates the re-expression of the fetal gene program in favour of slow $\beta$-MHC and downregulated SERCA2a. Low-dose T3 replacement or forced myocyte expression of Dio2 activity will prevent myocyte re-differentiation and decline in contractility (34-36).
Intracellular TH receptor (THR) is physically bound to myocyte enhancing factor (Mef)2 (37); their functional interaction activates $\beta$-MHC expression as adaptation (\#1b in Figure 1). Forced expression of one of its isoforms (Mef2 a, c or d), together with aortic banding, reduces contractile work and leads to a dilated cardiomyopathy (38-40). THR binding is downregulated in the failing heart (41). Collectively, reduced $\mathrm{T} 3$ and THR binding favour $\beta-\mathrm{MHC}$ reexpression with reduced contractile work.

During hyperadrenergic stressor states, catecholamine-driven $\mathrm{Ca}^{2+}$ entry via $\mathrm{L}$ type $\mathrm{Ca}^{2+}$ channels is enhanced leading to cytosolic $\left[\mathrm{Ca}^{2+}\right] \mathrm{i}$ and mitochondrial $\left[\mathrm{Ca}^{2+}\right] \mathrm{m}$ overload in cardiomyocytes $(42,43)$. The ensuing induction of oxidative stress by these organelles leads to myocyte activation of Dio3 to cause low intracellular T3 - a cardiac tissue-specific hypothyroid state that favours adaptation $\# 2$ in Figure 1. Concurrent store-operated $\mathrm{Ca}^{2+}$ channel entry with $\mathrm{Ca}^{2+}$ overload and oxidative stress occurs in response to other circulating hormones (eg, angiotensin II) and too may be contributory. Dhalla, et al (44) suggested intracellular $\mathrm{Ca}^{2+}$ overload and oxidative stress represent a common pathophysiological scenario operative in diverse stressor states.

An additional cardioprotective adaptation during hyperadrenergic states is the concordant downregulation of positive inotropic $\beta_{1}$ and $\beta_{2}$ adrenergic receptors, which account for the reduction in contractile reserve to dobutamine, a $\beta_{1}$ agonist (18). Manifest contractility and contractile reserve are further reduced by the upregulation of negative inotropic $\beta_{3}$ receptors presented as adaptation $\# 3$ in Figure 1 (45).

Collectively, this subcellular remodelling has the potential to be reversed and contractility to be rescued.

\section{REVERSING SUBCELLULAR REMODELLING}

The rescue of depressed contractility draws on reversing molecular signalling and attendant pathophysiological responses. CF-LVAD-induced optimal unloading of the failing heart has, as its objective, the reduction of left ventricular pressure and volume work and, thereby, the regression of hypertrophy and chamber dilation (3-5). A proportional reduction in ventricular mass and chamber volume must be obtained (normal mass/volume ratio 1.3) to avoid increments in systolic wall stress with impaired shortening (46). Reverse remodelling at the organ level includes a regression of fibrosis with its multiple adverse effects on myocardial structure and function $(47,48)$. Reductions in plasma and tissue natriuretic peptides - biomarkers of chamber distention and myocyte dedifferentiation (49) - also occur. Improvements in contractility and myocardial functional recovery with CF-LVAD support have been found in younger patients with nonischemic cardiomyopathy (3-5) and patients with a shorter duration of heart failure (50-52). In addition, recovery in EF has correlated with morphological findings that include smaller myocytes and less fibrosis at the time of device implantation (53,54). Prolonged LVAD unloading and/or body immobilization with bed rest, on the other hand, must be avoided because each favours cardiomyocyte and muscle atrophy, where fetal gene re-expression can be expected $(55,56)$. This finding is accentuated by data that found left ventricular function to already have improved as early as 30 days with the greatest degree of functional recovery within six months of LVAD implantation (4).

A reversal of systemic oxidative stress is essential to recovery and rescue of contractility $(57,58)$. This includes its role in the regulation of Dio2 and Dio3 deiodinases, with respective low T3 at systemic and cardiomyocyte levels. Enhancing endogenous antioxidant defenses can be used to attenuate redox stress (59-61). Pharmacological blockade of effector hormones of the activated renin-angiotensin-aldosterone and adrenergic nervous systems must also be addressed.

\section{SUMMARY}

Based on subcellular remodelling and myocyte adaptations, indexes of contractility will be reduced in the failing heart. Dedifferentiation of hypertrophied myocytes driven by low intracellular T3 signalling with re-expression of slow $\beta-\mathrm{MHC}$ coupled to downregulation of $\alpha-\mathrm{MHC}$ 
and SERCA2a is integral to these adaptations; so too is the concordant downregulation of $\beta_{1}$ and $\beta_{2}$ adrenergic and TH receptors with upregulation of negative inotropic $\beta_{3}$ receptors. These adaptations are invoked to preserve myocyte efficiency and, thereby, viability. Attendant reductions in subcellular remodelling with depressed indexes of myocardial contractility, however, can be rescued by antioxidants and a period

\section{REFERENCES}

1. Sonnenblick EH. Implications of muscle mechanics in the heart. Fed Proc 1962;21:975-90.

2. Harrison TR, Reeves TJ. Principles and problems of ischemic heart disease. Chicago: Year Book Medical Publications; 1968.

3. Morgan JA, Brewer RJ, Nemeh HW, et al. Left ventricular reverse remodeling with a continuous flow left ventricular assist device measured by left ventricular end-diastolic dimensions and severity of mitral regurgitation. ASAIO J 2012;58:574-7.

4. Drakos SG, Wever-Pinzon O, Selzman CH, et al. Magnitude and time course of changes induced by continuous-flow left ventricular assist device unloading in chronic heart failure: Insights into cardiac recovery. J Am Coll Cardiol 2013;61:1985-94.

5. Patel SR, Saeed O, Murthy S, et al. Combining neurohormonal blockade with continuous-flow left ventricular assist device support for myocardial recovery: A single-arm prospective study. J Heart Lung Transplant 2013;32:305-12.

6. Dhalla NS, Saini-Chohan HK, Rodriguez-Leyva D, Elimban V, Dent MR, Tappia PS. Subcellular remodelling may induce cardiac dysfunction in congestive heart failure. Cardiovasc Res 2009;81:429-38.

7. Lompre AM, Schwartz K, d'Albis A, Lacombe G, Van Thiem N, Swynghedauw B. Myosin isoenzyme redistribution in chronic heart overload. Nature 1979;282:105-7.

8. Alpert NR, Mulieri LA. Heat, mechanics, and myosin ATPase in normal and hypertrophied heart muscle. Fed Proc 1982;41:192-8.

9. Gustafson TA, Bahl JJ, Markham BE, Roeske WR, Morkin E. Hormonal regulation of myosin heavy chain and a-actin gene expression in cultured fetal rat heart myocytes. J Biol Chem 1987;262:13316-22.

10. Dhalla NS, Dent MR, Tappia PS, Sethi R, Barta J, Goyal RK. Subcellular remodeling as a viable target for the treatment of congestive heart failure. J Cardiovasc Pharmacol Ther.2006;11:31-45.

11. Liu X, Sentex E, Golfman L, Takeda S, Osada M, Dhalla NS. Modification of cardiac subcellular remodeling due to pressure overload by captopril and losartan. Clin Exp Hypertens 1999;21:145-56.

12. Takeo S, Elmoselhi AB, Goel R, Sentex E, Wang J, Dhalla NS. Attenuation of changes in sarcoplasmic reticular gene expression in cardiac hypertrophy by propranolol and verapamil. Mol Cell Biochem 2000;213:111-8.

13. Wang X, Ren B, Liu S, Sentex E, Tappia PS, Dhalla NS. Characterization of cardiac hypertrophy and heart failure due to volume overload in the rat. J Appl Physiol (1985) 2003;94:752-63.

14. Xu YJ, Chapman D, Dixon IM, Sethi R, Guo X, Dhalla NS. Differential gene expression in infarct scar and viable myocardium from rat heart following coronary ligation. J Cell Mol Med 2004;8:85-92.

15. Machackova J, Liu X, Lukas A, Dhalla NS. Renin-angiotensin blockade attenuates cardiac myofibrillar remodelling in chronic diabetes. Mol Cell Biochem 2004;261:271-8.

16. Wang J, Guo X, Dhalla NS. Modification of myosin protein and gene expression in failing hearts due to myocardial infarction by enalapril or losartan. Biochim Biophys Acta 2004;1690:177-84.

17. Shao Q, Ren B, Saini HK, Netticadan T, Takeda N, Dhalla NS. Sarcoplasmic reticulum $\mathrm{Ca}^{2+}$ transport and gene expression in congestive heart failure are modified by imidapril treatment. Am J Physiol Heart Circ Physiol 2005;288:H1674-82.

18. Bristow MR. b-adrenergic receptor blockade in chronic heart failure. Circulation 2000;101:558-69.

19. Schiattarella GG, Hill JA. Inhibition of hypertrophy is a good therapeutic strategy in ventricular pressure overload. Circulation 2015;131:1435-47.

20. Hill JA, Karimi M, Kutschke W, et al. Cardiac hypertrophy is not a required compensatory response to short-term pressure overload. Circulation 2000;101:2863-9.

21. Molkentin JD. Calcineurin-NFAT signaling regulates the cardiac hypertrophic response in coordination with the MAPKs. Cardiovasc Res 2004;63:467-75. of ventricular unloading, whose optimal duration will likely need to be determined for each patient.

DISCLOSURES: The authors have no financial disclosures or conflicts of interest to declare.

22. Konno T, Chen D, Wang L, et al. Heterogeneous myocyte enhancer factor-2 (Mef2) activation in myocytes predicts focal scarring in hypertrophic cardiomyopathy. Proc Natl Acad Sci U S A 2010;107:18097-102.

23. Ross J Jr. Afterload mismatch and preload reserve: a conceptual framework for the analysis of ventricular function. Prog Cardiovasc Dis 1976;18:255-64.

24. Monrad ES, Hess OM, Murakami T, Nonogi H, Corin WJ, Krayenbuehl HP. Time course of regression of left ventricular hypertrophy after aortic valve replacement. Circulation 1988;77:1345-55.

25. Lund $\mathrm{O}$, Erlandsen M. Changes in left ventricular function and mass during serial investigations after valve replacement for aortic stenosis. J Heart Valve Dis 2000;9:583-93.

26. Gupta M, Zak R. Reversibility of load-induced changes in myosin heavy chain gene expression. Am J Physiol 1992;262:R346-9.

27. Gao XM, Kiriazis H, Moore XL, et al. Regression of pressure overload-induced left ventricular hypertrophy in mice. Am J Physiol Heart Circ Physiol 2005;288:H2702-7.

28. Byrne NJ, Levasseur J, Sung MM, et al. Normalization of cardiac substrate utilization and left ventricular hypertrophy precede functional recovery in heart failure regression. Cardiovasc Res 2016;110:249-57.

29. Dahlof B. The importance of the renin-angiotensin system in reversal of left ventricular hypertrophy. J Hypertens 1993;11(3 Suppl):S29-S35.

30. Ascheim DD, Hryniewicz K. Thyroid hormone metabolism in patients with congestive heart failure: the low triiodothyronine state. Thyroid 2002;12:511-5.

31. Lamirand A, Pallud-Mothré S, Ramaugé M, Pierre M, Courtin F. Oxidative stress regulates type 3 deiodinase and type 2 deiodinase in cultured rat astrocytes. Endocrinology 2008;149:3713-21.

32. Wassen FW, Schiel AE, Kuiper GG, et al. Induction of thyroid hormone-degrading deiodinase in cardiac hypertrophy and failure. Endocrinology 2002;143:2812-5.

33. Pol CJ, Muller A, Zuidwijk MJ, et al. Left-ventricular remodeling after myocardial infarction is associated with a cardiomyocytespecific hypothyroid condition. Endocrinology 2011;152:669-79.

34. Weltman NY, Ojamaa K, Schlenker EH, et al. Low-dose T3 replacement restores depressed cardiac T3 levels, preserves coronary microvasculature and attenuates cardiac dysfunction in experimental diabetes mellitus. Mol Med 2014;20:302-12.

35. Trivieri MG, Oudit GY, Sah R, et al. Cardiac-specific elevations in thyroid hormone enhance contractility and prevent pressure overload-induced cardiac dysfunction. Proc Natl Acad Sci U S A 2006; 103:6043-6048

36. Minatoya Y, Ito K, Kagaya Y, et al. Depressed contractile reserve and impaired calcium handling of cardiac myocytes from chronically unloaded hearts are ameliorated with the administration of physiological treatment dose of T3 in rats. Acta Physiol (Oxf) 2007;189:221-31.

37. Lee Y, Nadal-Ginard B, Mahdavi V, Izumo S. Myocyte-specific enhancer factor 2 and thyroid hormone receptor associate and synergistically activate the alpha-cardiac myosin heavy-chain gene. Mol Cell Biol 1997;17:2745-55.

38. Xu J, Gong NL, Bodi I, Aronow BJ, Backx PH, Molkentin JD. Myocyte enhancer factors $2 \mathrm{~A}$ and $2 \mathrm{C}$ induce dilated cardiomyopathy in transgenic mice. J Biol Chem 2006;281:9152-62.

39. van Oort RJ, van Rooij E, Bourajjaj M, et al. MEF2 activates a genetic program promoting chamber dilation and contractile dysfunction in calcineurin-induced heart failure. Circulation 2006;114:298-308.

40. Kim Y, Phan D, van Rooij E, et al. The MEF2D transcription factor mediates stress-dependent cardiac remodeling in mice. J Clin Invest 2008;118:124-132.

41. Kinugawa K, Long CS, Bristow MR. Expression of TR isoforms in failing human heart. J Clin Endocrinol Metab 2001;86:5089-90. 
42. Fleckenstein A, Kanke J, Döring HJ, Leder O. Key role of Ca in the production of noncoronarogenic myocardial necroses. Recent Adv Stud Cardiac Struct Metab 1975;6:21-32.

43. Sayeed MM. Signaling mechanisms of altered cellular responses in trauma, burn, and sepsis: role of $\mathrm{Ca}^{2+}$. Arch Surg 2000;135:1432-42.

44. Dhalla NS, Golfman L, Takeda S, Takeda N, Nagano M. Evidence for the role of oxidative stress in acute ischemic heart disease: A brief review. Can J Cardiol 1999;15:587-93.

45. Niu X, Watts VL, Cingolani OH, et al. Cardioprotective effect of beta-3 adrenergic receptor agonism: role of neuronal nitric oxide synthase. J Am Coll Cardiol 2012;59:1979-87.

46. Feild BJ, Baxley WA, Russell RO Jr, et al. Left ventricular function and hypertrophy in cardiomyopathy with depressed ejection fraction. Circulation 1973;47:1022-31.

47. Butler CR, Jugdutt BI. The paradox of left ventricular assist device unloading and myocardial recovery in end-stage dilated cardiomyopathy: Implications for heart failure in the elderly. Heart Fail Rev 2012;17:615-33.

48. Weber KT, Sun Y, Bhattacharya SK, Ahokas RA, Gerling IC. Myofibroblast-mediated mechanisms of pathological remodelling of the heart. Nat Rev Cardiol 2013;10:15-26.

49. Altemose GT, Gritsus V, Jeevanandam V, Goldman B, Margulies KB. Altered myocardial phenotype after mechanical support in human beings with advanced cardiomyopathy. J Heart Lung Transplant 1997;16:765-73.

50. Dandel M, Weng Y, Siniawski H, et al. Pre-explant stability of unloading-promoted cardiac improvement predicts outcome after weaning from ventricular assist devices. Circulation 2012;126(11 Suppl 1):S9-19.

51. Birks EJ, Tansley PD, Hardy J, et al. Left ventricular assist device and drug therapy for the reversal of heart failure. $\mathrm{N}$ Engl J Med 2006;355:1873-84.

52. Goldstein DJ, Maybaum S, MacGillivray TE, et al. Young patients with nonischemic cardiomyopathy have higher likelihood of left ventricular recovery during left ventricular assist device support. J Card Fail 2012;18:392-5.
53. Bruckner BA, Razeghi P, Stetson S, et al. Degree of cardiac fibrosis and hypertrophy at time of implantation predicts myocardial improvement during left ventricular assist device support. J Heart Lung Transplant 2004;23:36-42.

54. Saito S, Matsumiya G, Sakaguchi T, et al. Cardiac fibrosis and cellular hypertrophy decrease the degree of reverse remodeling and improvement in cardiac function during left ventricular assist. J Heart Lung Transplant 2010;29:672-9.

55. Perhonen MA, Franco F, Lane LD, et al. Cardiac atrophy after bed rest and spaceflight. J Appl Physiol (1985) 2001;91:645-53.

56. Oriyanhan W, Tsuneyoshi H, Nishina T, Matsuoka S, Ikeda T, Komeda M. Determination of optimal duration of mechanical unloading for failing hearts to achieve bridge to recovery in a rat heterotopic heart transplantation model. J Heart Lung Transplant 2007;26:16-23.

57. Caruso R, Verde A, Campolo J, et al. Severity of oxidative stress and inflammatory activation in end-stage heart failure patients are unaltered after 1 month of left ventricular mechanical assistance. Cytokine. 2012;59:138-144.

58. Grosman-Rimon L, McDonald MA, et al. Markers of inflammation in recipients of continuous-flow left ventricular assist devices. Asaio J 2014;60:657-663.

59. Dhalla NS, Saini HK, Tappia PS, Sethi R, Mengi SA, Gupta SK. Potential role and mechanisms of subcellular remodeling in cardiac dysfunction due to ischemic heart disease. J Cardiovasc Med (Hagerstown) 2007;8:238-50.

60. Al Darazi F, Zhao W, Zhao T, et al. Small dedifferentiated cardiomyocytes bordering on microdomains of fibrosis: Evidence for reverse remodeling with assisted recovery. J Cardiovasc Pharmacol 2014;64:237-46.

61. Kamalov G, Zhao W, Zhao T, et al. Atrophic cardiomyocyte signaling in hypertensive heart disease. J Cardiovasc Pharmacol 2013;62:497-506. 